Pedo, B., Brandalise, F.M.P., Viana, D.D., Tzortzopoulos, P., Formoso, C.T., and Whitelock-Wainwright, A. 2020. "Digital Visual Management Tools in Design Management." In: Tommelein, I.D. and Daniel, E. (eds.). Proc. $28^{\text {th }}$ Annual Conference of the International Group for Lean Construction (IGLC28), Berkeley, California, USA, doi.org/10.24928/2020/0071, online at iglc.net.

\title{
DIGITAL VISUAL MANAGEMENT TOOLS IN DESIGN MANAGEMENT
}

\author{
Bárbara Pedó ${ }^{1}$, Fernanda M. P. Brandalise ${ }^{2}$, Daniela D. Viana ${ }^{3}$, Patricia \\ Tzortzopoulos $^{4}$, Carlos T. Formoso ${ }^{5}$, and Andrew Whitelock-Wainwright ${ }^{6}$
}

\begin{abstract}
Managing design often requires a complex organisational structure, due to the large number of internal and external stakeholders involved. That complexity demands an information system to support collaboration and coordination. However, traditional communication approaches only partially comply with the requirements of digital design environments. Visual Management (VM) has the potential to increase process transparency in design and facilitate the information transfer between stakeholders. Nonetheless, there is a lack of effective VM methods to support design management. The aim of this paper is to investigate the adoption of digital VM tools in design management. The paper presents findings of an ongoing research project developed with an infrastructure design company in the UK, following the Design Science Research approach. The main findings include the discussion of VM concepts in a digital design environment, as well as the analysis of existing VM tools which contribute to new ways of working and communicating.
\end{abstract}

\section{KEYWORDS}

Visual management, collaboration, integration, design management, digitalisation

\section{INTRODUCTION}

There are limitations on traditional approaches of communication in design (Hooper and Ekholm 2010). New tools are needed, seeking to reduce waste, increase value and enable continuous improvement (Koskela 1992; Sacks et al. 2009). Information transfer between stakeholders can be affected by the lack of system compatibility, resulting in rework and project overruns (Eastman et al. 2008). The lack of accurate information at critical

1 MSc Student, School of Engineering, Building Innovation Research Unit (NORIE), Universidade Federal do Rio Grande do Sul (UFRGS), Brazil, +44 7576632476, barbarapedo@gmail.com, orcid.org/0000-0002-6520-0981

2 PhD Candidate, School of Engineering, Building Innovation Research Unit (NORIE), Universidade Federal do Rio Grande do Sul (UFRGS), Brazil, fernandampbrandalise@gmail.com, orcid.org/00000001-5126-4741

3 Associate Professor, Interdisciplinary Department, Universidade Federal do Rio Grande do Sul (UFRGS), Brazil, danidietz@gmail.com, orcid.org/0000-0001-8958-4708

4 Professor, School of Art, Design and Architecture, University of Huddersfield, UK, P.Tzortzopoulos@hud.ac.uk, orcid.org/0000-0002-8740-6753

5 Associate Professor, School of Engineering, Building Innovation Research Unit (NORIE), Universidade Federal do Rio Grande do Sul (UFRGS), Brazil, formoso@ufrgs.br, orcid.org/0000$\underline{0002-4772-3746}$

6 Associate Technical Director, Arcadis, UK, andrew.whitelock-wainwright $@$ arcadis.com, orcid.org/0000-0002-0517-3563 
decision points can also result in a prolonged design process (Zirger and Hartley 1994). Methods to support design are needed, considering it is a complex process and, consequently, prone to errors.

Design often requires the coordination of a large number of professionals with a wide diversity of skills, and sharing information can be a challenge (Tribelsky and Sacks 2011). Hence, there is a need to coordinate the work of several stakeholders, ensuring communication effectiveness (Favela et al. 1993). Therefore, there is a need to improve the way information is managed and activities are carried out in the design process (Den Otter and Prins 2002). Communication, cooperation, and experience play a key role in supporting teamwork in collaborative processes (Emmitt et al. 2006). Lean principles have also been highlighted as an important way to improve process efficiency, supporting value generation (Koskela 2000).

One of the core Lean principles is increasing process transparency, which can benefit design management. Process transparency enables the main process flow to be visible and comprehensible to all stakeholders involved through direct observation of measurements, public display of information and physical means (Koskela 2000). It is also described as the ability of a process, or its parts, to communicate with all participants (Formoso et al. 2002). Process transparency can also support increased employees participation and involvement in the process, enabling the decision-making authority (Klotz et al. 2008), and allowing early detection of mistakes and deviations.

Visual management (VM) is a strategy to increase transparency (Tezel et al. 2016), and an approach to manage and control information. VM can support the identification of issues, reduction of waste and detection of inconsistencies (Tezel et al. 2016), contributing to cognitive, emotional and social benefits (Bresciani and Eppler 2008). According to Lindlöf (2014), visualisation can contribute to information flow management, supporting better handling of ambiguity and uncertainty in design, increasing the accessibility of information and supporting team communication.

VM can benefit from information technology so that the process of collecting, processing and displaying data becomes more efficient (Tezel and Aziz 2017). Nonetheless, the links between VM and information technology has been poorly explored in the literature (Tezel et al. 2015; Tezel and Aziz 2017). Moreover, VM applications in the design are scarce, mostly based on visual indicators that only transmit information to influence behaviour in a passive approach, presenting the information itself, and not how to improve the process (Galsworth 2017). Tjell and Bosch-Sijtsema (2015) and Tezel (2011) also highlighted that there are few studies exploring the implementation of VM in design, even though VM practices probably have already been in use in design management.

According to Den Otter and Prins (2002), teams have to become more collaborative and proactive in digital design environments. Digital technologies support visual representations with new data collection and processing capabilities (Killen and Kjaer 2012), allowing greater information storage and traceability.

Visual approaches can support faster decision making (Lindlöf 2014) through e.g. fast information feedback (Tezel et al. 2018; Valente et al. 2019), information accessibility and availability of real-time data collection and processing (Dallasega et al. 2018). Availability of information can also help in the improvement the understanding of schedules (Tezel and Aziz 2017) and increase operational capacity (Dallasega et al. 2018). In this context, VM should continue to provide information in a simple and easy way, 
thus digital technologies must support the process and not become a barrier to information access and transfer.

This paper presents the initial results of on-going research aiming to propose guidelines for the adoption of digital VM tools in design. It describes digital VM solutions adopted in the design management process of two infrastructure projects, focusing in design planning, control and coordination. The scope of the analysis is limited to highways and railways design projects.

\section{DIGITAL VM TOOLS IN DESIGN}

$\mathrm{VM}$ is a means to improve processes through collaboration, communication or transparency, instead of an end in itself(Valente et al. 2019). Visualisation tends to create more value to the final product when it is used to support collaboration between stakeholders (Valente et al. 2019). Collaborative and shared tools may have the ability to act as a boundary object, addressing different concerns simultaneously, being used as a common point of reference between users with different interests and allowing greater interaction and coordination between them (Nicolini 2007). Those objects are transported in time and space, legitimising decisions and mediating different interests (Nicolini 2007). According to Lindlöf (2014), there is a need to explore the challenges and implications of such objects connected with information technology (IT) based solutions in organisations that have distributed teams.

There are different types of VM tools (Tezel et al. 2016). For example, according to Valente et al. (2019), the maturity stages grow from dynamic tools used for (i) performance evaluation and activity coordination; (ii) reflection, planning, and decision making; and (iii) collaboration. Brandalise (2018) proposed a taxonomy of VM practices in three categories of communication and integration: (i) one to one, (ii) one to many or many to one, and (iii) many to many (see table 1). The taxonomy enables understanding of how information is shared between users, i.e. in which way communication occurs between information senders and receivers, and how much the VM practice is integrated to management routines.

Table 1: Taxonomy of advanced practices of VM systems (adapted from Brandalise (2018))

\begin{tabular}{|c|c|c|}
\hline One to one & One to many or Many to one & Many to many \\
\hline $\begin{array}{c}\text { Clear channel of } \\
\text { communication between a } \\
\text { sender and a receiver. } \\
\text { Collaboration may occur in the } \\
\text { design of the VM tool, but it is } \\
\text { not widely observed in its use. } \\
\text { Low level of integration with } \\
\text { management routines. } \\
\text { Ex.: Andon, Kanban, and poka- } \\
\text { yoke. }\end{array}$ & $\begin{array}{l}\text { Practices that coordinate } \\
\text { activities of many stakeholders, } \\
\text { allowing data sets to be } \\
\text { analysed concurrently to } \\
\text { produce routine information prior } \\
\text { to decision making. } \\
\text { Intermediate level of integration } \\
\text { with management routines. } \\
\text { Ex.: customization marking, and } \\
\text { target dates of production } \\
\text { decided collaborativaly. }\end{array}$ & $\begin{array}{l}\text { Enable communication and } \\
\text { decision making between } \\
\text { many users and between } \\
\text { departments, using highly } \\
\text { dynamic VM practices as } \\
\text { support. } \\
\text { Highest level of integration } \\
\text { with management routines. } \\
\text { Ex.: board of shop floor } \\
\text { management, and prototypes. }\end{array}$ \\
\hline
\end{tabular}

New opportunities are emerging due to the use of digital technologies in construction, helping to capture, test, verify and validate information, as well as supporting management, construction, use, operation and maintenance processes (Chen and Kamara 2008; Tezel et al. 2016; Koskela et al. 2018). Such practices can encourage digitalisation 
or even automation, supporting collaboration between stakeholders. According to Tezel and Aziz (2017), managing the continuous information transfer between all stakeholders in a construction project is still a major challenge despite the recent technological improvements, such as the availability and accessibility to relevant information in a quick, easy and accurate way. Digital technology has contributed to extend the range of VM applications, improving (a) visibility with constantly changing interface innovations; (b) temporal capacity through greater information gathering, storage and analysis; (c) problem-solving capabilities, supported by automation of information processing and the ability to cross geographic boundaries through high connectivity (Murata 2018).

Constructs related to the adoption of VM systems in digital design have been identified in the literature as:

Simplicity of functioning: traditional VM tools are designed to be simple to understand and use so the information transfer gives autonomy to stakeholders (Liker and Hoseus 2009). Simplicity can be related to the use and functioning of a VM tool (Saurin et al. 2006), allowing easy changes during its use.

Information Standardisation: it supports the reduction of time in searching for data, and deliver more consistent and up-to-date information, also providing only the information needed (Laine et al. 2014). It can help to avoid misinterpretations, preventing loss of time to understand information (Alarcón and Mardones 1998).

Autonomy to plan and control: ensuring high product and process quality can be achieved by providing autonomy to humans or machines to identify errors and mistakes (Liker 2004). This involves transparency and understanding of processes by all team members, as they are well placed to evaluate the quality of their own the activities (Hopp and Spearman 2004). Autonomy also requires decentralisation of information, as it encourages a greater involvement of team members in decision making and problem detection (Valente et al. 2019).

Right amount of information available: VM assumes that information should be 'pulled' by any member at any time, which does not follow a linear flow (Greif 1991; Sacks et al. 2010; Lee 2018). Excess of information or early availability of information can lead to excess production and create confusion in the process sequence. This highlights the importance of pulling information when needed (Ohno 1988), i.e. the availability of the right information for the right purpose at the right time.

Easy information accessibility: Easy access to information in data gathering and processing (Tezel et al. 2016), facilitating the capture of relevant information for the process and context. VM tools should be easy to access, to understand and to update (Valente et al. 2019).

Flexibility: This relates to the flexibility to make changes in VM tools as needed (Barth et al. 2019). Visualisation can be dynamically modified according to dynamic interactions (Eppler and Bresciani 2013), i.e. tools with customisable interfaces can better deal with unexpected changes in the environment or with context specifications. It is also related to the adaptability of information to different contexts and users, for instance when companies present distributed teams and there is a need of boundary objects to integrate them. In this context, VM tools are considered as means of communication between individuals with different perceptions which need to work together and create a common point of view (Lindlöf 2014).

Information traceability: ability to track decisions throughout the project process (Whyte et al. 2016). A systematic approach to track and store information can potentially allow a faster feedback of changes during the process. 


\section{RESEARCH METHOD}

Design Science Research (DSR) was the methodological approach adopted in this investigation (Holmström et al. 2009). It involves an iterative process between problem understanding and solution development, in incremental learning cycles (Lukka 2003). DSR was adopted due to the prescriptive character of this investigation. An empirical study was carried out with an infrastructure design company from the UK, named Company A. This research consisted of a critical analysis of visual tools used by Company A to support design management within a digital environment. This company operates in highways and railways construction projects, and has been chosen due to the fact that it had implemented several Lean practices and VM digital tools to support design management. Data from two projects were analysed in this investigation.

The study is divided into three phases, according to Holmström et al. (2009), presented in Figure 1. The first phase includes an understanding of the problem, looking at the company's design processes and VM tools. The second phase is based on an understanding of issues and identification of VM benefits and barriers. The last phase is the analysis and reflection on the integration of VM tools with design. There were iterative cycles of analysis, understanding, development and refinement of the artefact between the phases, supporting incremental learning cycles.

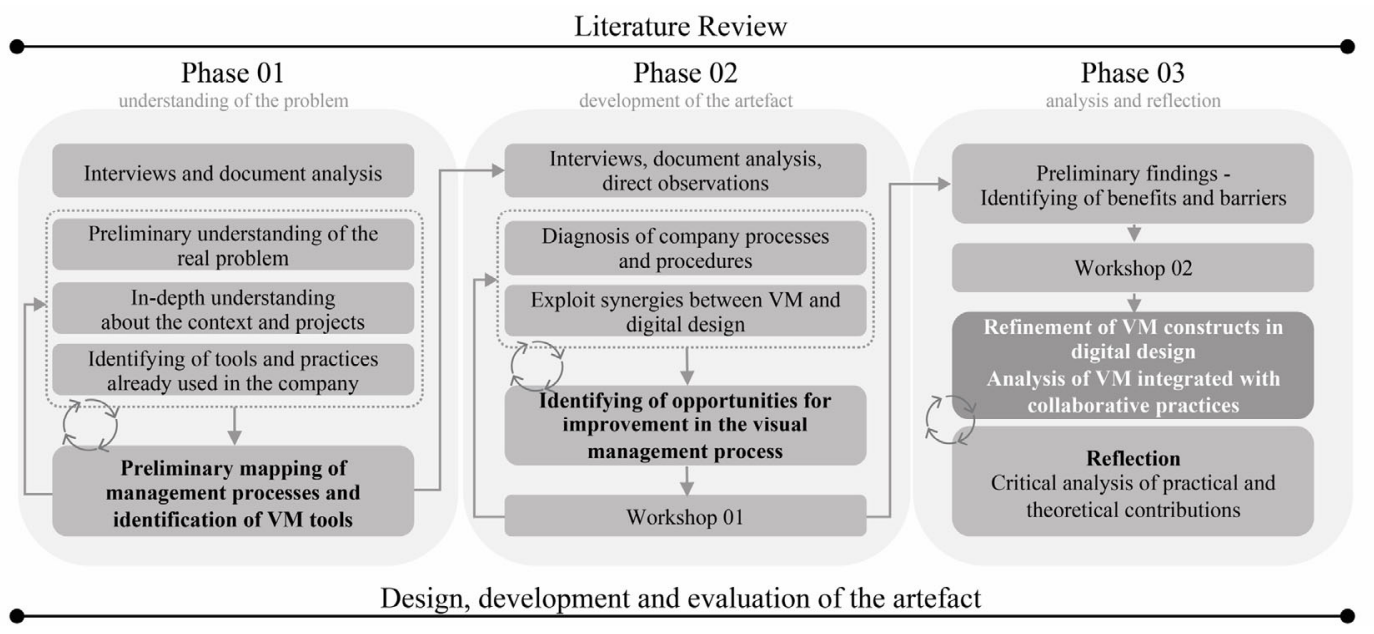

Figure 1: Research design overview

Based on the types of complexity proposed by Bertrand and Muntslag (1993), the context in which this investigation was carried out can be described as highly complex: (i) structural complexity associated to a wide range of internal and external stakeholders with interdependent design decisions around the world - 18 disciplines, contractor, subcontracted companies, users/community, public and local authorities, client, and consequent issues related to the understanding of processes by all team members; (ii) product specification uncertainty, as infrastructure projects can present several particular specifications related to the size and duration of projects, and (iii) process uncertainty, considering the need of adjusting the process according to client's needs.

The main sources of evidences were: (i) nine interviews with design team members, project directors and managers, BIM managers and professionals involved on the project development team; (ii) twelve direct observations of project meetings; (iii) analysis of 
design documents and VM tools interfaces; (iv) two workshops with key project members, including managers and coordinators.

\section{RESULTS}

\section{ANALYSIS OF VM TOOLS}

Company A has a design management system based on lean concepts. Different types of meetings are carried out regularly, some for design planning and control and others for coordination. The planning and control process includes different hierarchical levels, similarly to the Last Planner System (Ballard and Howell 2003; Ballard and Tommelein 2016): (i) master planning, used to define milestones and the master schedule; (ii) phase scheduling, in which a high-level detailed programme is collaboratively developed; (iii) look-ahead monthly meetings, in which constraints are identified and removed; (iv) weekly short-term planning, control and coordination meetings, to coordinate design, activities and deliverables. There are also daily meetings, used to coordinate design and verify daily progress inside of each discipline; and also lessons learnt workshops and meetings at the end of each project or stage. The meetings are virtual or face-to-face, as teams are distributed in different offices and countries.

VM tools were used to support design planning, control and coordination at tactical (look-ahead monthly meetings) and operational levels (weekly short-term meetings), as shown in Figure 2.

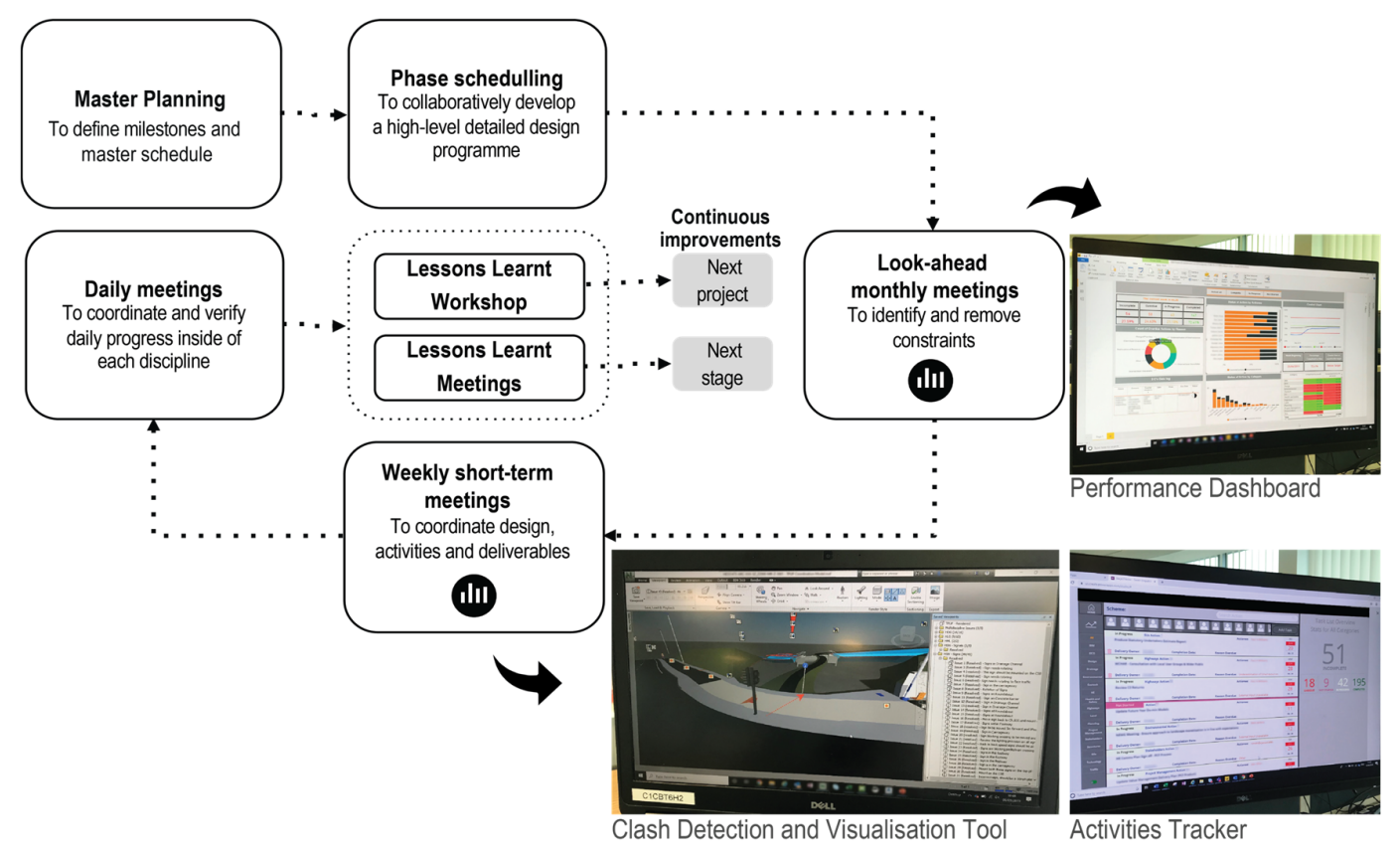

Figure 2: Design management activities and digital VM tools adopted at Company A

The activities tracker (Figure 2) is a digital tool used to support weekly meetings. The software interface is customised according to the company' users needs and there are iterative cycles to improve the tool interface during design development, prioritising the information needed by stakeholders. The main objective is to support the control of each design discipline and update them weekly during the meeting. Only the disciplines involved in the current design stage take part of the meeting, allowing for a dynamic and 
quick meeting (30 minutes). The discussion focus on the planned start/finish/completion dates and reason for overdue activities. All team members have access to the digital tool all the time. During the meetings, the tool is displayed on the project managers screen, enabling information to be shared. The tool is used at an operational level, supporting meetings between disciplines; however, the information has the potential to support operational activities inside each discipline as well.

The performance dashboard (Figure 2) is a digital visual tool used in monthly meetings to display planning and control performance metrics. The data used to create the performance metrics comes from information collected through the activity's tracker. This tool can be accessed and easily updated by lead members of the design team. The dashboard includes the following metrics: reasons for the non-completion of work packages, Percentage Plan Complete (PPC), and 3C's method to identify cause, concern and countermeasure. The digital dashboard also identifies the status of the actions which can be filtered by actionee or category/discipline, as well as a control chart, supporting the monitoring of the PPC per week compared with the average PPC and the target. It mainly helps project managers and directors in analysing the team progress through weekly PPC and reasons for the non-completion of work packages. The 3C's strategy is not always adopted due to the fact the input of information comes from another, independent tool, which makes it difficult to access and update. Company A also adopts lagging indicators, which are 'output' oriented and can potentially stifle the improvement processes. The interface of the tools varies according to the user; thus, project manager, coordinators and team member leads have access to different interfaces and contents.

The clash detection and visualisation tool (see Figure 2) is used in weekly design coordination meetings. This tool is used to create a BIM federated model, identify clashes between disciplines, visualise combined models and help assure the quality processes between disciplines. The integrated model is visualised during meetings to drive discussions and support design decisions. The federated model is available to the design team, and is used to track design decisions and disciplines interdependencies. Nevertheless, it is not easily updated, and the BIM manager retains a central role in the integration and transfer of information.

\section{DisCUSSION}

Participant observation in planning meetings indicated that the company uses VM in a fragmental way, i.e. digital VM tools are used at specific points in time for specific design management activities. Those tools frequently support collaboration of stakeholders in meetings. However, these have been implemented mostly at the tactical and operational level between disciplines, without sufficient consideration of the user needs at operational levels inside of each discipline. In fact, the company recently started to encourage the use of digital VM tools at the team level, so that there is a stronger connection to other planning levels and to increase the engagement in their adoption.

The literature review constructs were used to assess the implementation of the three VM digital tools, using three levels of adoption: full, partial or non-adoption (see Table 2). The activities tracker tool can be classified as the most advanced in this context as it adopts almost all VM concepts. By contrast, the other tools lack the application of some VM concepts, such as autonomy, information availability, information accessibility, simplicity of functioning, easy understanding, as well as flexibility and adaptability of information to different contexts and users. 
Table 2: Classification of tools according to VM concepts

\begin{tabular}{cccc}
\hline $\begin{array}{c}\text { Functional and aesthetics } \\
\text { requirements } \\
\text { of VM tools }\end{array}$ & \multicolumn{2}{c}{ Tools to plan and control } & $\begin{array}{c}\text { Tools to coordinate } \\
\text { design activities }\end{array}$ \\
\cline { 2 - 4 } Simplicity of functioning & $\begin{array}{c}\text { Activities } \\
\text { tracker }\end{array}$ & $\begin{array}{c}\text { Performance } \\
\text { dashboards }\end{array}$ & $\begin{array}{c}\text { Clash Detection and } \\
\text { Visualisation Tool }\end{array}$ \\
Information standardisation & $\mathrm{A}$ & $\mathrm{NA}$ & NA \\
Autonomy to plan and control & $\mathrm{PA}$ & $\mathrm{A}$ & $\mathrm{A}$ \\
Availability of information & $\mathrm{A}$ & $\mathrm{NA}$ & $\mathrm{PA}$ \\
Easy information accessibility & $\mathrm{A}$ & $\mathrm{NA}$ & $\mathrm{PA}$ \\
Flexibility of tools & $\mathrm{A}$ & $\mathrm{PA}$ & $\mathrm{PA}$ \\
Traceability of information & $\mathrm{A}$ & $\mathrm{PA}$ & $\mathrm{NA}$ \\
\hline Legend: Adopted (A) & Partially adopted (PA) & Not adopted (NA)
\end{tabular}

There is limited use of some VM tools, such as performance dashboards and clash detection/visualisation tool, due to difficulties faced by team members in accessing the tools or the right information, as the tools are based in a cloud system and users have no knowledge and skills in tracking the tool. The performance dashboard is not easy to access, considering there is no clarity about how to use the tool and where to find the information (information within it is not explicit), consequently, team members and discipline leads were unaware of such performance dashboards at an operational level.

Some specific metrics from the tool are sent in reports to the team members as a static information, reinforcing the lack of real-time information availability (see table 2). The integration of the performance dashboard in the weekly meetings could assist in the adoption of the tool and the initial training to introduce the tools' aims and functions to all stakeholders can support a greater understanding. The challenges of the clash detection/visualisation tool are mainly related to the regular sharing of information as teams tend not to share information as often as it would be necessary. It also can be related to the partial adoption of the information availability concept, as the right amount of information is not available when needed during the design process.

Excess of information is pointed in the literature by Murata (2018) as an issue related to a waste of visualisation in digital environments. The overload of information and unnecessary details can lead to waste, such as misunderstandings. When combined with a lack of information prioritisation can cause issues related to the effective use of information and the selection of the right information (for the right purpose), also affecting the simplicity and flexibility of tools. The overload of information created by the excess of information available can result in difficulties to find and select the information needed and, consequently, affecting the engagement of the team with the tool, as well as creating barriers to access the information. These concepts were identified in performance dashboards and the clash detection/visualisation tool as partially or nonadopted concepts. Moreover, the clash detection/visualisation tool presents an amount of information and unnecessary detail inside of BIM models and it can generate issues related to the ability to prioritise and select the right information, but also regarding the maintenance and update of such information detailed. There is also a need to decentralise the use of performance dashboards. This can be achieved by giving project teams access 
to the dashboards, enabling them to have more responsibility to control and evaluate their own activities.

The use of VM tools in design management needs to be relevant to the entire team. Teams can benefit from work routines, adding value to the design process through effective interactions. Digital VM tools usually involve more users than traditional VM tools, and the transfer of information between stakeholders can be classified as 'one to many', 'many to one' and/or 'many to many' (Table 3).

The tool classified as most advanced according to the concepts described above is also the tool which should be used by a large number of people ('many to many'). This can be related to information availability, accessibility, and autonomy concepts, as the right amount of information is available; it is easy to access, understand and update; as well as there is a decentralisation of information and decision-making, allowing independent use of the tools by all stakeholders.

Table 3: Identification of users involved in the transfer of information (adapted from Brandalise (2018))

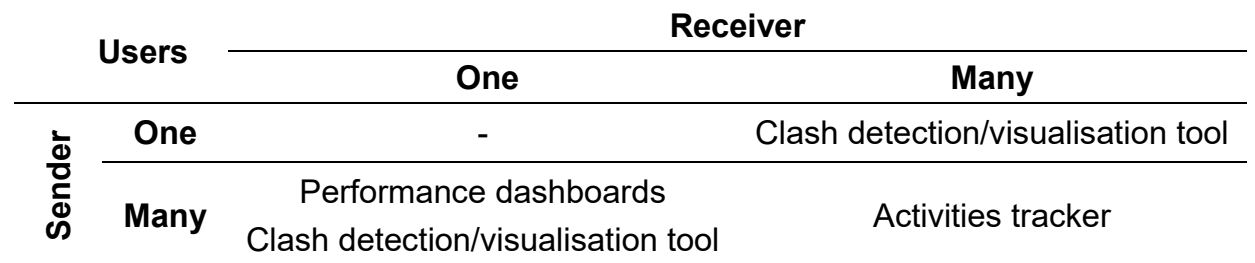

The clash detection/visualisation tool is used by different stakeholders and disciplines throughout the process. However, the information transfer is not fully integrated, i.e., the model is sent from each discipline to the BIM manager ('many to one'), then the federated model is shared with all disciplines and guide the discussion during the coordination meetings. After the discussion, the federated model is available to all disciplines and each of them can incorporate the changes in their own models ('one to many'). Considering the existing approach for communication and integration, the tool can be categorised in 'many to one' and 'one to many', supporting the coordination of many stakeholders and analysis of data concurrently at different moments. It partially adopts the concept of accessibility and availability of information. The performance dashboard is the less integrated tool, as it is created with team members input information, but only the project manager uses it effectively ('many to one'). It does not adopt the concepts of information availability and decentralisation.

Benefits from the use of tools at the company were identified through qualitative data from direct observations and interviews regarding digital VM tools in company $\mathrm{A}$, including: (i) increased team productivity due to easy access to appropriate and accurate information by geographically distributed teams, (ii) reduction of design management time by increasing the decentralisation of information and considering more effective interactions; (iii) efficient communication and faster feedback related to the ability to track design decisions and changes through a systematic approach during the design; and (iv) greater visibility of activities and design processes, resulting in a greater shared understanding and stakeholders' engagement and motivation, enabling the team to become more committed to the activities and more autonomous. By contrast, barriers related to the fragmented flow of information between stakeholders can be described as (i) lack of team members' engagement in the use of tools and (ii) inadequacy of the tools 
to the process, which can be described as: the need of a cultural change in the regular sharing of information, excess of information combined with a lack of information prioritisation, and effective use of information.

\section{FINAL COMMENTS}

This paper presents results of an on-going investigation which aims to propose recommendations for the adoption of digital VM in design. The proposed classification of VM tools explored the potential benefits and barriers of each tool investigated. It helps to better understand the effectiveness of VM tools, by analysing relevant constructs related to the adoption of digital VM strategies in design, as well as investigating the integration with stakeholders. These are the main findings so far: (i) digital tools still lack some traditional VM characteristics, such as simplicity and flexibility, affecting its efficiency in use; and (ii) digital tools have the potential to integrate many stakeholders as they involve many users and disciplines in different ways of communication with 'many to many', 'many to one' or 'one to many' interactions. This research is limited to the study of three tools, further work should explore a substantial number of digital VM tools, encouraging a further reflection about the benefits and barriers.

\section{REFERENCES}

Alarcón, L. F., and Mardones, D. A. 1998. "Improving the Design-Construction Interface." Proc. 6th Ann. Conf. Int. Group for Lean Construction, Guarujá, Brazil, 1998.

Ballard, G., and Howell, G. 2003. "An update on last planner." Proc. 11th Ann. Conf. Int. Group for Lean Construction, Virginia, USA, 1-10.

Ballard, G., and Tommelein, I. 2016. "Current Process Benchmark for the Last Planner System." Lean Construction Journal, 13(1), 57-89.

Barth, K. B., Formoso, C. T., and Sterzi, M. P. 2019. "Performance Measurement in Lean Production Systems: An Exploration on Requirements and Taxonomies." Proc. 27th Ann. Conf. Int. Group for Lean Construction, Dublin, Ireland, 629-640

Bertrand, J. W. M., and Muntslag, D. R. 1993. "Production control in engineer-to-order firms." Int. J. Prod. Econ., 30(31), 3-22.

Brandalise, F. M. P. 2018. "Método de Avaliação de Sistemas de Gestão Visual na Produção da Construção Civil." MSc Thesis, Building Innovation Research Unit (NORIE), Universidade Federal do Rio Grande do Sul (UFRGS), Brazil

Bresciani, S., and Eppler, M. J. 2008. "The risks of visualization - a classification of disadvantages associated with graphic representations of information." ICA Working Paper, 1-22.

Chen, Y., and Kamara, J. M. 2008. "Using mobile computing for construction site information management." Engineering, Construction and Architectural Management, 15(1), 7-20.

Dallasega, P., Rauch, E., and Linder, C. 2018. "Industry 4.0 as an enabler of proximity for construction supply chains: A systematic literature review." Comput. Ind., Elsevier, 99(March), 205-225.

Den Otter, ad F., and Prins, M. 2002. "Architectural design management within the digital design team." Engineering, Construction and Architectural Management, 9(3), 162 173.

Eastman, C., Teicholz, P., Sacks, R., and Liston, K. 2008. BIM handbook: A guide to building information modeling for owners, managers, designers, engineers and contractors. John Wiley and Sons, Inc., Hoboken, New Jersey. 
Emmitt, S., Sander, D., and Chritoffersen, A. K. 2006. "Implementing of Value Through Lean Design management." In: Bertelsen, S. and Formoso, C.T., Proc. 12th Ann. Conf. Int. Group for Lean Construction, Helsingør, Denmark.

Eppler, M. J., and Bresciani, S. 2013. "Visualization in management: From communication to collaboration. A response to Zhang." J. Visual Lang. Comput., 24(2), 146-149.

Favela, J., Wong, A., and Chakravarthy, A. 1993. "Supporting collaborative engineering design." Eng. Comput., 9(3), 125-132.

Formoso, C. T., Santos, A. dos, and Powell, J. A. 2002. "An exploratory study on the applicability of process transparency in construction sites." Journal of Construction Research, World Scientific, 3(1), 35-54.

Galsworth, G. D. 2017. Visual Workplace Visual Thinking: Creating Enterprise Excellence Through the Technologies of the Visual Workplace. Second Edition. Taylor and Francis, Boca Raton London New York.

Greif, M. 1991. The Visual Factory: Building Participation through Shared Information. Productivity Press, Portland, Oregon.

Holmström, J., Ketokivi, M., and Hameri, A.-P. 2009. "Bridging practice and theory: a design science approach.” Decision Sciences, Wiley Online Library, 40(1), 65-87.

Hooper, M., and Ekholm, A. 2010. "A pilot study: Towards BIM integration - An analysis of design information exchange and coordination.” Proc. CIB W78 27th International Conference, Cairo, Egypt.

Hopp, W. J., and Spearman, M. L. 2004. "To Pull or Not to Pull: What is the Question?" MandSom-Manuf. Serv. Op., 6(2), 133-148.

Killen, C. P., and Kjaer, C. 2012. "Understanding project interdependencies: The role of visual representation, culture and process." Int. J. Proj. Manag., Elsevier Ltd, 30(5), 554-566.

Klotz, L., Horman, M., Bi, H. H., and Bechtel, J. 2008. "The impact of process mapping on transparency." Int. J. of Productivity and Performance Management, 57(8), 623636.

Koskela, L. 1992. Application of the new production philosophy to construction. Technical Report \# 72, Center for Integrated Facility Engineering. Department of Civil Engineering. Stanford University, 75 p.

Koskela, L. 2000. "An exploration towards a production theory and its application to construction." VTT Technical Research Centre of Finland.

Koskela, L., Tezel, A., and Tzortzopoulos, P. 2018. "Why Visual Management?” Proc. 26th Ann. Conf. Int. Group for Lean Construction, Chennai, India, 250-260.

Laine, E., Alhava, O., and Kiviniemi, A. 2014. "Improving Built-in Quality By Bim Based Visual Management.” In:, Kalsaas, B. T., Koskela, L. and Saurin, T. A., Proc. 27th Ann. Conf. Int. Group for Lean Construction, Oslo, Norway, pp. 945-95

Lee, H. L. 2018. "Big Data and the Innovation Cycle.” Prod. Oper. Manage., 27(9), 16421646.

Liker, J. K. 2004. The Toyota Way: 14 Management Principles from the World's Greatest Manufacturer. CWL Publishing Enterprises, Inc., Madison.

Liker, J. K., and Hoseus, M. 2009. "Human Resource development in Toyota culture." International Journal of Human Resources Development and Management, 10(1), 34.

Lindlöf, L. 2014. Visual Management - on Communication in Product Development Organizations. PhD Diss., Department of Technology Management and Economics, Chalmers University of Technology, Sweden. 
Lukka, K. 2003. "The constructive research approach." Case study research in logistics. Publications of the Turku School of Economics and Business Administration, Series B, 1(2003), 83-101.

Murata, K. 2018. "A Study on Digital Visual Management for Providing Right Transparency against Emergencies." Proc. 22nd Cambridge International Manufacturing Symposium, University of Cambridge, 27 - 28 September 2018.

Nicolini, D. 2007. "Studying visual practices in construction." Build Res. Inf., 35(5), 576580.

Ohno, Taiichi. 1988. Toyota production system. Productivity Press, Cambridge, MA. 143 p.

Sacks, R., Koskela, L., Dave, B. A., and Owen, R. 2010. "Interaction of Lean and Building Information Modeling in Construction." J Constr Eng M, 136(9), 968-980.

Sacks, R., Treckmann, M., and Rozenfeld, O. 2009. "Visualization of Work Flow to Support Lean Construction.” J Constr Eng M, 135(12), 1307-1315.

Saurin, T. A., Formoso, C. T., and Cambraia, F. B. 2006. "Towards a Common Language Between Lean Production and Safety Management." Proc. 14th Ann. Conf. Int. Group for Lean Construction, Santiago, Chile, pp. 483-495.

Tezel, A., and Aziz, Z. 2017. "From conventional to it based visual management: A conceptual discussion for lean construction." J Inform Technol in Construction, Vol. 22, 220-246, http://www.itcon.org/2017/12

Tezel, A., Koskela, L., and Tzortzopoulos, P. 2016. "Visual management in production management: A literature synthesis." Journal of Manufacturing Technology Management, 27(6), 766-799.

Tezel, A., Koskela, L., Tzortzopoulos, P., Formoso, C. T., and Alves, T. 2015. "Visual Management in Brazilian Construction Companies: Taxonomy and Guidelines for Implementation." J Manage Eng, 31(6), 05015001.

Tezel, B. A. 2011. "Visual management: an exploration of the concept and its implementation in construction." PhD Diss., University of Salford, 341.

Tjell, J., and Bosch-Sijtsema, P. M. 2015. "Visual Management in Mid-sized Construction Design Projects.” Proc Econ Financ, 21(2014), 193-200.

Tribelsky, E., and Sacks, R. 2011. "An empirical study of information flows in multidisciplinary civil engineering design teams using lean measures." Architectural Engineering and Design Management, 7(2), 85-101.

Valente, C. P., Brandalise, F. M. P., and Formoso, C. T. 2019. "Model for Devising Visual Management Systems on Construction Sites.” J Constrn Eng M, 145(2), 04018138.

Whyte, J., Tryggestad, K., and Comi, A. 2016. "Visualizing practices in project-based design: tracing connections through cascades of visual representations." Engineering Project Organization Journal, Taylor and Francis, 6(2-4), 115-128.

Zhang, K. 2012. "Using visual languages in management." J Visual Lang Comput, Elsevier, 23(6), 340-343.

Zirger, B. J., and Hartley, J. L. 1994. "A conceptual model of product development cycle time." J Eng and Technol Manage, 11(3-4), 229-251. 